\title{
Verification of atmospheric plasma irradiation as an alternative control method for Tribolium castaneum (Herbst)
}

\author{
A. M. Hassan ${ }^{a}$ (D), T. M. Sileem ${ }^{b}$ (D) and R. S. Hassan ${ }^{b *}$ (D) \\ ${ }^{a}$ Accelerators and Ion Sources Department, Nuclear Research Center, Atomic Energy Authority, \\ P.O. Box 13759, Abo-Zaabal, Egypt

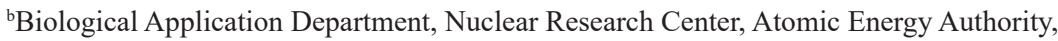 \\ P.O. Box 13759, Abo-Zaabal, Egypt \\ *e-mail: redahassan424@gmail.com
}

Received: April 13, 2019 - Accepted: April 30, 2019 - Distributed: August 31, 2020

(With 3 figures)

\begin{abstract}
Radio frequency plasma, RF plasma, has been applied to a number of industrial applications. Laboratory experiments were conducted to determine the RF plasma potential in Tribolium castaneum (Herbst) control. Three treatment variables: (1) helium or argon plasmas; (2) two power levels (50 and 100 watt); and (3) different RF plasma exposure times $(0,20,40,60$ and 90 seconds) were examined in this study. The susceptibility of $T$. castaneum to treatment varies as gas, power level, and the exposure time varies. A positive correlation was found between insect mortality percent in treating larvae as well as treated pupae and exposure time to RF plasma and also the power level of irradiation. The results revealed that no live insects were found after a 90 second, 100 watt helium RF plasma treatment. The survival percents of the adults were developed from treated larvae and treated pupae were significantly reduced by increasing of the exposure time or power level. Obtained data indicated that the treatment with RF plasma might be considered as an environmentally compatible or alternative supplement to the other control methods for stored product-pests management.
\end{abstract}

Keywords: RF plasma, irradiation treatment, Tribolium castaneum, mortality, latent effect.

\section{Verificação da irradiação plasmática atmosférica como método alternativo de controle para Tribolium castaneum (Herbst)}

\section{Resumo}

Plasma de radiofrequência, plasma de RF, tem sido empregado em diversas aplicações industriais. Experimentos de laboratório foram conduzidos para determinar o potencial de plasma de RF no controle de Tribolium castaneum (Herbst). Foram examinados nesse estudo três variáveis de tratamento: (1) plasma de hélio ou argônio; (2) dois níveis de potência (50 e 100 watts); e (3) diferentes tempos de exposição ao plasma de RF (0, 20, 40, 60 e 90 segundos). A suscetibilidade do T. castaneum ao tratamento varia conforme o gás, o nível de energia e o tempo de exposição. Foi encontrada uma correlação positiva dentre a porcentagem de mortalidade de insetos no tratamento de larvas, bem como as pupas tratadas e o tempo de exposição ao plasma de RF, e também o nível de potência da irradiação. Os resultados revelaram que não foram encontrados insetos vivos após 90 segundos, com 100 watts de tratamento com plasmas de hélio e RF. As porcentagens de sobrevivência dos adultos foram desenvolvidas a partir de larvas tratadas, e as pupas tratadas foram significativamente reduzidas pelo aumento do tempo de exposição ou nível de potência. Os dados obtidos indicaram que o tratamento com plasma de RF pode ser considerado como um suplemento ambientalmente compatível ou alternativo aos outros métodos de controle para o manejo de produtos-pragas armazenados.

Palavras-chave: plasma de RF, tratamento de irradiação, Tribolium castaneum, mortalidade, efeito latente.

\section{Introduction}

The red flour beetle, Tribolium castaneum (Herbst), is a cosmopolitan pest of flour mills, ware houses, and other post-harvest food processing structures. The presence of T. castaneum in post-harvest food processing structures causes economic losses due to contamination of products with $T$. castaneum which causes both quantitative and qualitative damage (Bhargava and Kumawat, 2010), in addition to the potential costs involved with control measures. T. castaneum populations can be difficult to control since they exploit cracks, crevices and refugia inside equipment or in the building structure (Campbell et al., 2002). Damage is caused mainly by the larvae and adults, 
which feed extensively on previously holed or broken grains, or grains damaged by other pests. With the general phase-out of methyl bromide, which was completed in Jan 2005 (EPA, 2004), the need for safe, environmentally friendly and effective alternatives to methyl bromide are greatly needed. Several technologies have been proposed as alternatives, but shortcomings generally result from unreasonably long treatment times (2-3 d), high cost, temperature limits of application, changes to the aesthetics of the product, negative environmental effects, and acceptance by the public. One alternative, which has been of interest to our laboratories, has been the use of non-thermal plasma, NTP $(0.1-2.0 \mathrm{eV})$. Gases treated with high energy lose electrons and get driven by electromagnetic interactions instead of hydrodynamic forces producing plasma. The advantage of using NTP as a method of controlling insect pests is that plasma can be produced at ambient temperatures with reasonable electrical power requirements. The chemically reactive species produced by the plasma are not excessive. There is no ionizing radiation, and the plasma is effective against insects but safe for the end-user and the environment (Donohue et al., 2006). Bures (2004) found that a low temperature $(0.1-2.0 \mathrm{eV})$ induced death in green peach aphids, Myzus persicae S. human body lice, Pediculus humanus humanus $\mathrm{L}$. and citrus mealy bugs, Planococcus citri R. when these different pests were treated in their substances. Mortality, malformation and the emergence of offspring were observed (Abd El-Aziz et al., 2014; Mohammadi et al., 2015) in Plodia interpunctella, Tribolium confusum and Ephestia kuehniella. And because there are no published reports on the effects of Radio frequency plasma, RF plasma on the insects and no mechanistic studies have been conducted on insects, the development of a practical scale discharge sterilization device for quarantine requires a number of studies to ensure that this approach is feasible. The aim of the current laboratory experiments was to determine the effect of RF plasma on immature stages of $T$. castaneum including finding out the effect of different exposure times, power level of RF plasma and type of inert gas together with finding out of a non-chemical method on T. castaneum.

\section{Material and Methods}

\subsection{Insect culture}

T. castaneum used in experiments were derived from a laboratory culture initially established from adults collected from infested wheat in Stored Product Pests Unit. Adults were reared on a rearing media composed of wheat flour and $5 \%$ brewer's yeast $(19: 1, \mathrm{w} / \mathrm{w})$ over several generations (Ayvaz et al., 2002). The flour was disinfested at $60^{\circ} \mathrm{C}$ for $10 \mathrm{hr}$ to eliminate possible contaminants (Tuncbilek and Kansu, 1996). Throughout the experiments, insect cultures were maintained under controlled laboratory conditions of $30 \pm 2{ }^{\circ} \mathrm{C}$ and $70 \pm 2 \%$ relative humidity and continuous darkness.

\subsection{Experimental procedure}

A schematic of the experimental setup consists of the $13.65 \mathrm{MHz}$ radio frequency (RF) generator with automatic tuner, the plasma chamber, the feeding with the plasma gas system and the vacuum system. The antenna is fed by a 0-600 Watt (w), 13.56 MHz RF generator (AG 0613) complete with the automatic matching network (AIT/MIT-600) to maximize the power transfer efficiency from the RF generator to the plasma. Both the RF generator and the auto matching network are from $\mathrm{T} \& \mathrm{C}$ Power Conversion Inc., USA. Around the source chamber, two coils allow an on-axial magnetic field which provides 0-200 Gauss. This magnetic field confines the plasma electrons which increase the plasma density. The insect sample holder is a Pyrex bottle where the plasma irradiation is performed. In the present experiment, the Helium (He) and Argon (Ar) were utilized as a precursor gas to create plasma, and each of them is used separately.

\subsection{Bioassay}

Fifteen to seventeen-d old larvae of T. castaneum were exposed to helium and argon plasma for 0 (control), 20, 40, 60 and $90 \mathrm{sec}$ at two power level 50 and $100 \mathrm{w}$ into the Pyrex bottle. Three replicates (30 larvae per replicate) were used for each treatment and control, thus we thought that this numbers are enough to make block based experimental design. Similarly one to three-d old pupae were exposed to the same treatments with, three replicates (20 pupae per replicate) was used for each treatment and control. The treated and non treated insects were then maintained in the laboratory to observe insect's mortality. For the treated larvae, pupal formation, adult emergence and percent of mortality were recorded. In the case of the treated pupae, adult emergence and percent of mortality were recorded. The remaining adults per replicate, emerging from irradiated larvae or irradiated pupae, were transferred by a fine brush to glass jars containing $20 \mathrm{~g}$ of rearing media. These adults were observed for surviving of them and their progeny as an indication of reproductive ability.

\subsection{Statistical analysis}

All statistical analyses were performed with SSPS computer program version 17.0 (SPSS, ) using the PROC GLM procedure.

\section{Results}

\subsection{Effect of RF plasma treatment on larvae}

The effect RF plasma on larvae including larval mortality percent, pupation, emergence, survival from larvae to adulthood percents, of the red flour beetle, treated with helium and argon RF plasma for different exposure times, is presented in Table 1. The exposure time of $90 \mathrm{sec}$. to helium RF plasma at $100 \mathrm{w}$ power level caused zero pupation percent and led to significant decrease in the population growth compared to control, while the exposure time of $20 \mathrm{sec}$ caused $86.7 \%$ and $87.6 \%$ pupation respectively, at 50 and $100 \mathrm{w}$ power levels of helium RF plasma respectively 
Table 1. Pupation, larval mortality, adult emergence, and survival from larvae to adulthood \% of the treated Tribolium castaneum as larvae with helium and argon RF plasma.

\begin{tabular}{|c|c|c|c|c|c|c|}
\hline Gas type & Power level & $\begin{array}{c}\text { Exposure } \\
\text { times }\end{array}$ & $\%$ Of pupation & $\begin{array}{c}\% \text { Of larval } \\
\text { mortality }\end{array}$ & $\begin{array}{l}\% \text { Of adult } \\
\text { emergence }\end{array}$ & $\begin{array}{l}\% \text { Of survival } \\
\text { from larvae to } \\
\text { adulthood }\end{array}$ \\
\hline \multirow[t]{10}{*}{ Helium } & 50watt & $0 \mathrm{~s}$ & $96.3 \pm 0.41^{\mathrm{A} *}$ & $3.7 \pm 0.45^{\mathrm{P}}$ & $92.8 \pm 0.59^{\mathrm{A}}$ & $88.8 \pm 0.38^{A}$ \\
\hline & & $20 \mathrm{~s}$ & $86.7 \pm 0.36^{\mathrm{D}}$ & $13.3 \pm 0.46^{\mathrm{o}}$ & $92.3 \pm 0.59^{\text {В }}$ & $82.5 \pm 0.38^{\mathrm{AB}}$ \\
\hline & & $40 \mathrm{~s}$ & $80.5 \pm 0.35^{\mathrm{F}}$ & $19.5 \pm 0.46^{\mathrm{K}}$ & $88.4 \pm 0.57^{\mathrm{D}}$ & $63.3 \pm 0.36^{\mathrm{E}}$ \\
\hline & & $60 \mathrm{~s}$ & $77.4 \pm 0.35^{\mathrm{G}}$ & $22.6 \pm 0.45^{\mathrm{J}}$ & $68.2 \pm 0.56^{\mathrm{L}}$ & $32.0 \pm 0.35^{\mathrm{FG}}$ \\
\hline & & $90 \mathrm{~s}$ & $33.4 \pm 0.32^{\mathrm{N}}$ & $66.6 \pm 0.48^{\mathrm{C}}$ & $60.0 \pm 0.55^{\circ}$ & $22.0 \pm 0.35^{\mathrm{G}}$ \\
\hline & 100watt & 0s & $96.3 \pm 0.41^{\mathrm{A}}$ & $3.7 \pm 0.45^{\mathrm{P}}$ & $92.8 \pm 0.59^{\mathrm{A}}$ & $88.8 \pm 0.38^{\mathrm{A}}$ \\
\hline & & $20 \mathrm{~s}$ & $87.6 \pm 0.37^{\mathrm{C}}$ & $12.4 \pm .046^{\mathrm{M}}$ & $78.9 \pm 0.57^{\mathrm{J}}$ & $62.9 \pm 0.36^{\mathrm{DE}}$ \\
\hline & & $40 \mathrm{~s}$ & $77.4 \pm 0.35^{\mathrm{G}}$ & $22.6 \pm 0.46^{\mathrm{J}}$ & $70.6 \pm .057^{\mathrm{K}}$ & $57.6 \pm 0.36^{\mathrm{E}}$ \\
\hline & & $60 \mathrm{~s}$ & $28.6 \pm 0.21^{\mathrm{O}}$ & $71.4 \pm 0.47^{\text {в }}$ & $64.7 \pm 0.56^{\mathrm{N}}$ & $21.7 \pm 0.35^{\mathrm{G}}$ \\
\hline & & $90 \mathrm{~s}$ & $0.0 \pm 0.0^{\mathrm{P}}$ & $100.0 \pm 0.00^{\mathrm{A}}$ & $0.0 \pm 0.0^{\mathrm{P}}$ & $0.0 \pm 0.0^{\mathrm{P}}$ \\
\hline \multirow[t]{10}{*}{ Argon } & 50watt & $0 \mathrm{~s}$ & $96.3 \pm 0.41^{\mathrm{A}}$ & $3.7 \pm 0.45^{\mathrm{P}}$ & $92.8 \pm 0.59^{\mathrm{A}}$ & $88.8 \pm 0.38^{\mathrm{A}}$ \\
\hline & & $20 \mathrm{~s}$ & $93.0 \pm 0.38^{\text {в }}$ & $7.0 \pm 0.45^{\mathrm{N}}$ & $92.3 \pm 0.59^{\text {в }}$ & $76.7 \pm 0.37^{\mathrm{BC}}$ \\
\hline & & $40 \mathrm{~s}$ & $84.7 \pm 0.31^{\mathrm{E}}$ & $15.3 \pm 0.46^{\mathrm{L}}$ & $85.8 \pm 0.58^{\mathrm{F}}$ & $75.4 \pm 0.37^{\mathrm{BC}}$ \\
\hline & & $60 \mathrm{~s}$ & $71.8 \pm 0.34^{\mathrm{II}}$ & $28.2 \pm 0.46^{\mathrm{H}}$ & $83.1 \pm 0.57^{\mathrm{H}}$ & $57.6 \pm 0.36^{\mathrm{E}}$ \\
\hline & & $90 \mathrm{~s}$ & $53.3 \pm 0.33^{\mathrm{L}}$ & $46.7 \pm 0.49^{\mathrm{E}}$ & $82.2 \pm 0.57^{\mathrm{I}}$ & $36.7 \pm 0.35^{\mathrm{F}}$ \\
\hline & 100watt & 0s & $96.3 \pm 0.41^{\mathrm{A}}$ & $3.7 \pm 0.45^{\mathrm{P}}$ & $92.8 \pm 0.59^{\mathrm{A}}$ & $88.8 \pm 0.038^{\mathrm{A}}$ \\
\hline & & $20 \mathrm{~s}$ & $76.6 \pm 0.35^{\mathrm{H}}$ & $23.4 \pm 0.46^{\mathrm{I}}$ & $91.7 \pm 0.59^{\mathrm{C}}$ & $84.0 \pm 0.038^{\mathrm{AB}}$ \\
\hline & & $40 \mathrm{~s}$ & $68.3 \pm 0.34^{\mathrm{J}}$ & $31.7 \pm 0.47^{\mathrm{G}}$ & $87.0 \pm 0.58^{\mathrm{E}}$ & $71.1 \pm 0.037^{\mathrm{CD}}$ \\
\hline & & $60 \mathrm{~s}$ & $60.6 \pm 0.33^{\mathrm{K}}$ & $39.4 \pm 0.48^{\mathrm{F}}$ & $85.0 \pm 0.58^{\mathrm{G}}$ & $52.3 \pm 0.036^{\mathrm{E}}$ \\
\hline & & $90 \mathrm{~s}$ & $35.8 \pm 0.32^{\mathrm{M}}$ & $64.2 \pm 0.48^{\mathrm{D}}$ & $66.7 \pm 0.56^{\mathrm{M}}$ & $28.8 \pm 0.035^{\mathrm{FG}}$ \\
\hline
\end{tabular}

*Means in the same column followed by the same letters do not differ significantly $(P<0.05)$.

compared to $96.3 \%$ in control. Argon RF plasma caused $35.8 \%$ pupation at applying $100 \mathrm{w}$ power levels for an exposure time of $90 \mathrm{sec}$ which increased by decreasing the exposure times and power level to reach $93 \%$ and $76.6 \%$ at the power levels 50 and $100 \mathrm{w}$ respectively for the exposure time $20 \mathrm{sec}$ (Table 1). Similar conclusions from separated means were secured in the case of adult emergence. The adult emergence percent was zero at the $90 \mathrm{sec}, 100 \mathrm{w}$ power level of helium RF plasma, while it reached $96.7 \%$ at the $20 \mathrm{sec}, 50 \mathrm{w}$ power level of helium RF plasma like the adult emergence in control treatment it was $92.8 \%$. A non-considerable adult emergence effect $(68.7 \%)$ occurred at $100 \mathrm{w}$ power levels for $90 \mathrm{sec}$ exposure time in comparison to $97 \%$ at the control. Survival from larvae to adulthood percent decreased with increasing the exposure time and the power level, and, thus, the lowest percentage (zero and 21.6) was obtained with the $90 \mathrm{sec}$ and $60 \mathrm{sec}$ at $100 \mathrm{w}$ power levels of helium RF plasma. In general, helium RF plasma showed better entomocidal activity than argon RF plasma at various treatments and the power level of $100 \mathrm{w}$ proved to be more effective against the pest than the power level of $50 \mathrm{w}$ (Table 1).

\subsection{Effects of RF plasma treatment on pupae}

The data in Figure 1 shows that RF plasma affected the pupal mortality percentage of the treated pupae (1-3 d-old). Both types of RF plasma at $100 \mathrm{w}$ had a significantly high mortality effect on $T$. castaneum pupae $(F=51.22$, and $P<0.01)$. It is mean that the increase of power level to 100 watts led to increase significantly in mortality percentages at either helium or argon RF plasma comparing with 50 watt for them.

It is apparent from this figure that the maximum mortality (100\%) was achieved at $90 \mathrm{sec}$ helium RF plasma compared to $71.4 \%$ in the $90 \mathrm{sec}$ argon RF plasma. However, the minimum, $47.8 \%$ and $35.1 \%$, was observed in the $20 \mathrm{sec}$ helium and argon RF plasma treatments respectively in Figure 2. In addition, both helium and argon RF plasma treatments were found to be very effective in reducing the adult emergence from treated pupae. It can be seen from Figure 2 that negative relationships are present between the exposure times and adult emergence percent as well as the power levels and adult emergence percent for both type of gases $(\mathrm{F}=14.7$, and $P<0.01)$.

\subsection{Effect of RF plasma treatment on survival of adults emerging from treated larvae}

The effect of irradiation with helium and argon RF plasma for different exposure times at both power levels on the survival of the adults which developed from irradiated larvae of T. castaneum are presented in Figures 1 and 3.

Results of ANOVA showed that the survival \% significantly varied with power level and exposure times of helium RF plasma irradiation from the begging till the end of the experiment in compared to control Figure 1. We should mention that at $100 \mathrm{w}$ power levels and an exposure time $90 \mathrm{sec}$ of helium RF plasma irradiation to larvae, the mortality \% was $100 \%$ and no adults emerged. 

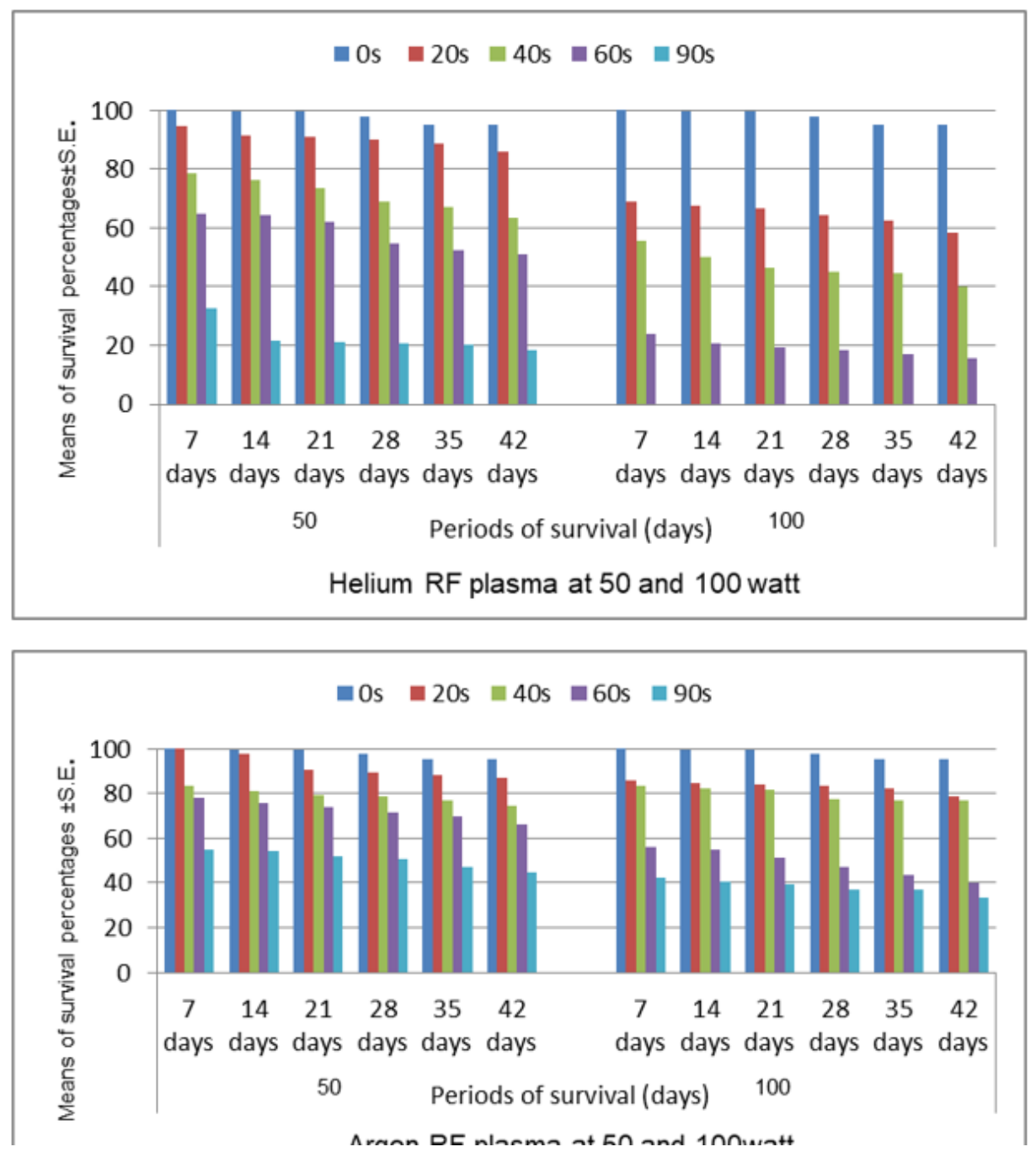

Figure 1. Effect of RF plasma irradiation on the survival of adults emerging from irradiated Tribolium castaneum as a larvae. $\pm \mathrm{SE}$ (stander error).

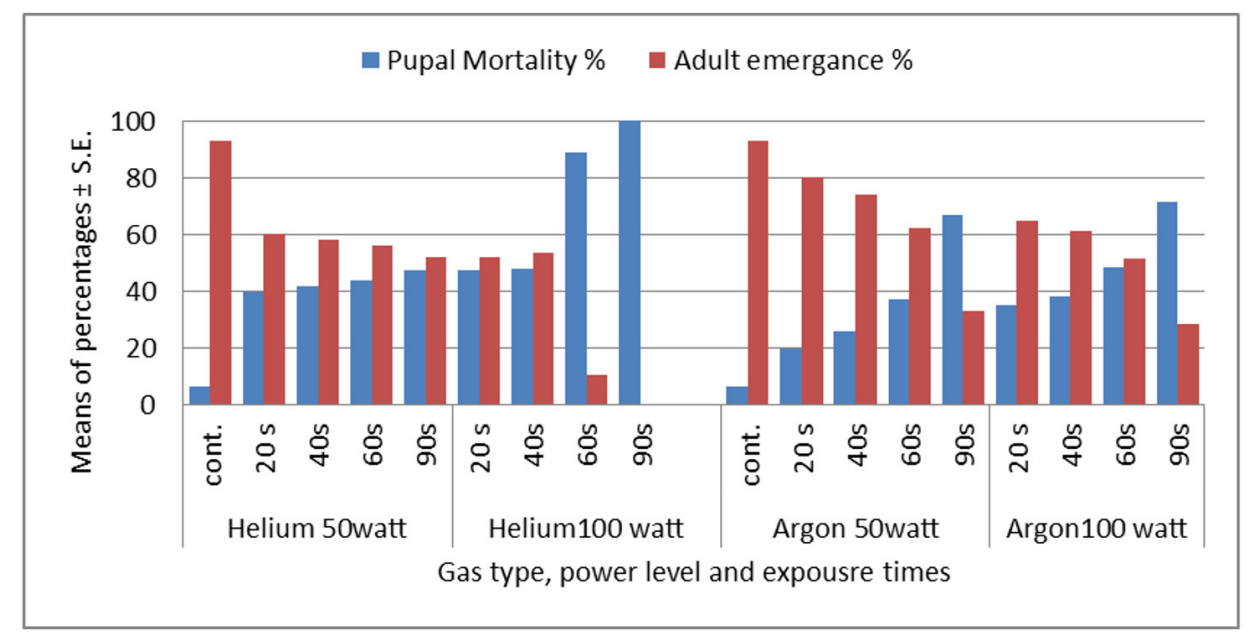

Figure 2. Pupal mortality and adult emergence percentages of Tribolium castaneum influenced by different exposure times of helium and argon at 50 and 100 watt power levels as pupae. \pm SE (stander error). 
Also, at the helium RF plasma remaining exposure times, emerged adults were decreased significantly compared to the control larvae. As the exposure time of helium RF plasma irradiation increased, the survival of T. castaneum decreased. The highest dose (exposure time of $60 \mathrm{sec}$ at a $100 \mathrm{w}$ power level) caused $24.1 \%$ survival in the first seven days after treatment and decreased to $15.7 \%$ survival at the end of observation period Figure 1.

\subsection{Effect of RF plasma treatment on survival of adults emerging from treated pupae}

Similarly, there was significant decrease in the surviving of adult that resulting from treated pupae, at the power levels and the exposure times to helium and argon RF plasma irradiation. Thus same reduction trend in the adult survival rate form treated pupae was noted within observation period Figure 3. At the shortest exposure period of $20 \mathrm{sec}$, the produced adult survival resulting from irradiated pupae of $T$. castaneum was $64.1 \& 54.4 \%$ and $97.3 \& 70.7 \%$ respectively, at power levels 50 and $100 \mathrm{w}$ to helium and argon RF plasma in the first $7 \mathrm{~d}$ after treatment and decreased to $56.4 \& 44.0 \%$ and $77.7 \& 56.4 \%$ respectively at the end of the observation period. However, the percent of adult survival, resulting from irradiated pupae, was $55.1 \& 44.7 \%$ at the $90 \mathrm{sec} 50 \mathrm{w}$ to helium and argon RF plasma and $0.0 \& 35.5 \%$ at the $90 \mathrm{sec} 100 \mathrm{w}$ to helium and argon RF plasma and then it decreased to $31.9 \& 16.9 \%$ and $0.0 \& 28.1 \%$ at $42 \mathrm{~d}$ from irradiation Figure 3 . In most cases, there were no obvious differences in adult's survival between different observation periods either in the case of treated larvae or in the case of treated pupae. Moreover, T. castaneum pupae seem to be more susceptible than T. castaneum larvae at the same power level and the same exposure time for single gas.
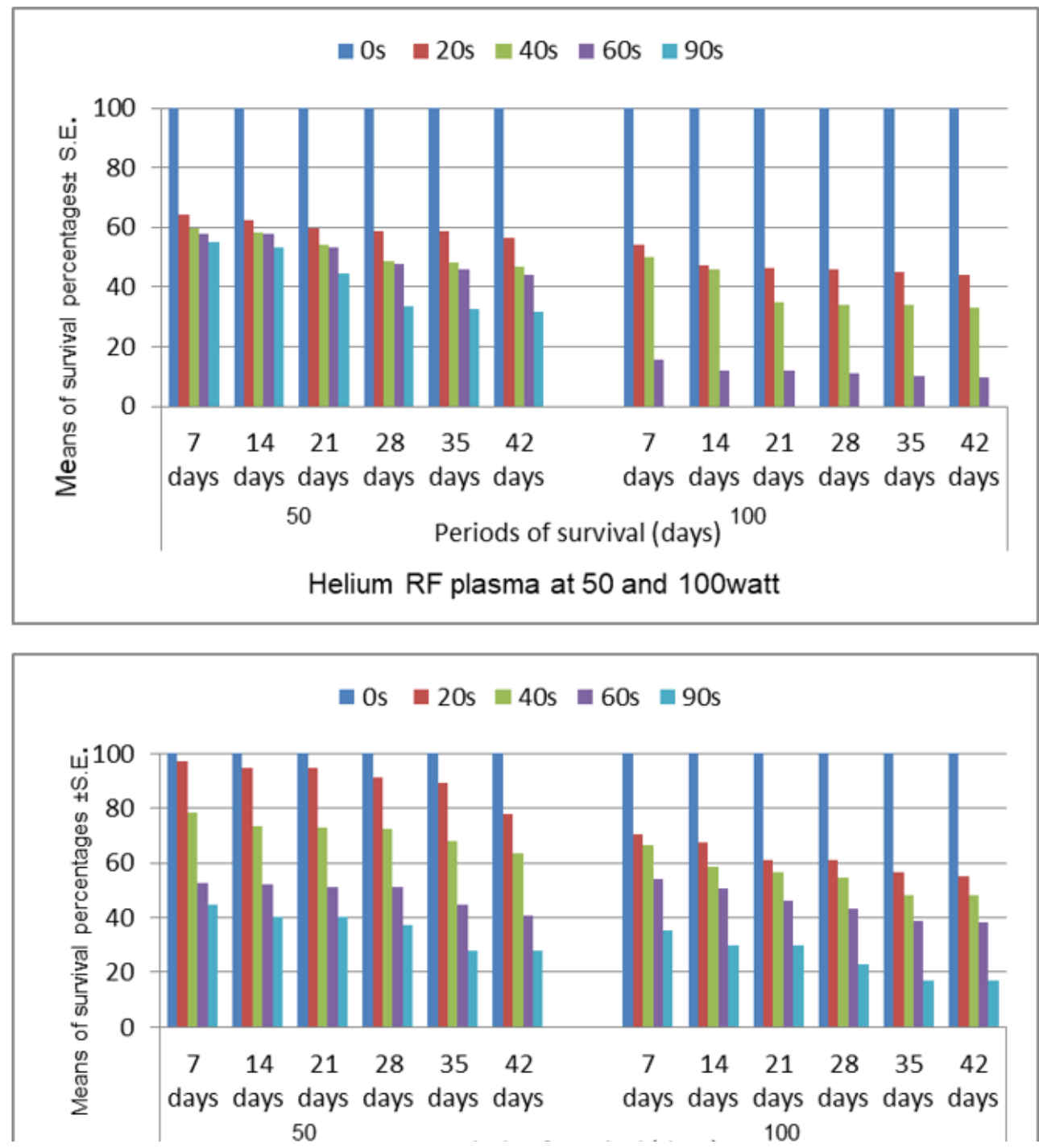

Figure 3. Effect of RF plasma irradiation on the survival of adults emerging from irradiated Tribolium castaneum as a pupae. \pm SE (stander error). 


\section{Discussion}

Various insects cause quantitative and qualitative losses in stored products every year. Chemical pesticides are widely used to control stored product pests (Konradsen et al., 2003). Concerns about resistance to insecticides, as well as their environmental impact, have stimulated researchers to find out an alternative pest control methods. A favored substitute might be the application of non-thermal plasma discharge methods. Application of this plasma to living organisms was proved. The entomocidal activity of RF plasma against T. castaneum is highly influenced by the power levels of 50 and $100 \mathrm{w}$, exposure times $(20-90 \mathrm{sec})$ and inert gases, helium and argon. Our results showed that the increasing power level and exposure times affected larval mortality, pupation and adult emergence when $T$. castaneum larvae were irradiated. This result was in agreement with the findings (Mohammadi et al., 2015), who reported that the mortality of Tribolium confusum and Ephestia kuehniella was increased directly with the increase of exposure time. In the current study, the exposure of T. castaneum pupae to RF plasma treatment decreased the percentage of adult emergence and increased the pupal mortality with increasing exposure time or power level. Where the exposure time of $90 \mathrm{sec}$ at $100 \mathrm{w}$ in helium RF plasma treatment prevented the emergence of treated pupae. Similar results have been reported for the other insects (Abd El-Aziz et al., 2014; Mohammadi et al., 2015). Their studies proved that the adults' emergence of Plodia interpunctella, Tribolium confusum and Ephestia kuehniella was significantly reduced by increasing power level and exposure times. The adults, were developed from different treatments (gas type, power level, and exposure time), exhibited significant reduction in the surviving percent at all observation periods from 7 to 42 days. In agreement with (Keever et al., 2001), our data stated that treating larvae and pupae with helium and argon RF plasma radiation at the powers of 50 and $100 \mathrm{w}$ for different exposure times $(20-90 \mathrm{sec})$ reduced the ability of emerging adults to produce adult progeny. According to many authors, the hazardous impacts could be due to charge accumulation on the outer surface of the membrane that induces an electrostatic force, which can overcome the tensile strength of the membrane, causing its rupture (Mendis et al., 2000; Bures et al., 2006). Jaworek et al. (1996) has shown that helium discharges are capable of chemically modifying dielectric materials in a DBD (change the chemical structure of carbon-based materials such as polymers and hydrocarbons). A similar effect is possible on the surface of insects. It is well established that damage to the hydrocarbon, wax layer on the surface of insect cuticle, can result in dehydration and insect mortality (Chapman, 1998). The plasma site of action seems to be the insect nervous system, neuromuscular system, or both. Exposure to plasma caused hyper excitability, which seemed to increase metabolic rate and water loss, but it had no effect on the abundance of cuticular hydrocarbons (Donohue et al., 2006). Abd El-Aziz et al. (2014) reported that non-thermal plasma causes oxidative damage in $P$. interpunctella larvae.
Generally, possible RF plasma has been demonstrated as a very useful tool for many pest controls. The RF plasma irradiation is a recently proposed technology for different applications in agriculture, pest control, and food industry. This is a promising procedure as it leaves no chemical residues on products, safe to operators and has minimal impact (Shintan and Sakudo, 2016) on the environment compared to chemical processing. The present results concluded that exposure to helium at $100 \mathrm{w}$ can be used as an insecticidal agent against $T$. castaneum at relatively long exposure time $90 \mathrm{sec}$.

\section{References}

ABD EL-AZIZ, M.F., MAHMOUD, E.A. and EL-ARAGI, G.M., 2014. Non thermal plasma for control of the Indian meal moth, Plodia interpunctella (Lepidoptera: pyralidae). Journal of Stored Products Research, vol. 59, pp. 215-221. http://dx.doi. org/10.1016/j.jspr.2014.03.002.

AYVAZ, A., OZTURK, F., YARAY, K. and KARAHASTIOGLU, E., 2002. Effects of gamma radiation and Malathion on confused flour beetle, Tribolium confusum. Pakistan Journal of Biological Sciences, vol. 5, no. 5, pp. 560-562. http://dx.doi.org/10.3923/ pjbs.2002.560.562.

BHARGAVA, M.C. and KUMAWAT, K.C., 2010. Insect pests of stored grains and grain product pests of stored grains and their management. New Delhi: New India Publishing Agency, pp. 29-70.

BURES, B.L., 2004. Rapid mortality of pest arthropods by direct exposure to a dielectric barrier discharge. Raleigh: North Carolina State University, 160 p. Ph.D. Dissertation.

BURES, B.L., DONOHUE, K.V., ROE, R.M. and BOURHAM, M.A., 2006. Nonchemical dielectric barrier discharge treatment as a method of insect control. IEEE Transactions on Plasma Science, vol. 30, no. 1, pp. 55-62. http://dx.doi.org/10.1109/ TPS.2005.863595

CAMPBELL, J.F., MULLEN, M.A. and DOWDY, A.K., 2002. Monitoring stored-product pests in food processing plants with pheromone trapping, contour mapping, and marker capture. Journal of Economic Entomology, vol. 95, no. 5, pp. 1089-1101. http:// dx.doi.org/10.1093/jee/95.5.1089. PMid:12403439.

CHAPMAN, R.F., 1998. The insects-structure and function. 4th ed. Cambridge: Cambridge University Press. http://dx.doi. org/10.1017/CBO9780511818202.

DONOHUE, K.V., BURES, B.L., BOURHAM, M.A. and ROE, R.M., 2006. Mode of action of a novel nonchemical method of insect control: atmospheric pressure plasma discharge. Journal of Economic Entomology, vol. 99, no. 1, pp. 38-47. http://dx.doi. org/10.1093/jee/99.1.38. PMid:16573321.

ENVIRONMENTAL PROTECTION AGENCY - EPA, 2004. Protection of stratospheric ozone: process for exempting critical uses from the phaseout of methyl bromide: final rule. Washington: EPA, pp. 76982-77009. Federal Register, no. 69.

JAWOREK, H.A., KRUPA, A. and CZECH, T., 1996. Backcorona generated plasma for decomposition of hydrocarbon gaseous contaminants. Journal of Physics D: Applied Physics, vol. 29, no. 9, pp. 2439-2446. http://dx.doi.org/10.1088/0022$3727 / 29 / 9 / 031$. 
KEEVER, D., DOWDY, A.K., BURES, B.L., HANKINS, O.E. and BOURHAM, M.A., 2001. Mortality and sterility of the cigarette beetle, Lasioderma serricorne (F.), due to exposure to atmospheric plasma. In: Proceedings of the 2001 Annual Research Conference on Methyl Bromide Alternatives and Emissions Reductions, 2001, San Diego, California. San Diego: MBAO, pp. 1-4.

KONRADSEN, F., VAN DER HOEK, W., COLE, D.C., HUTCHINSON, G., DAISLEY, H., SINGH, S. and EDDLESTON, M., 2003. Reducing acute poisoning in developing countriesoptions for restricting the availability of pesticides. Toxicology, vol. 192, no. 2-3, pp. 249-261. http://dx.doi.org/10.1016/S0300483X(03)00339-1. PMid:14580791.

MENDIS, D.A., ROSENBERG, M. and AZAM, F., 2000. A note on the possible electrostatic disruption of bacteria. IEEE
Transactions on Plasma Science, vol. 28, no. 4, pp. 1304-1306. http://dx.doi.org/10.1109/27.893321.

MOHAMMADI, S., IMANI, S., DORRANIAN, D., TIRGARI, S. and SHOJAEE, M., 2015. The effect of non- thermal plasma to control of stored product pests and changes in some characters of wheat materials. Food Engineering Reviews, vol. 7, pp. 150-156.

SHINTAN, H. and SAKUDO, A., 2016. Gas plasma sterilization in microbiology. Norfolk: Caister Academic Press.

TUNCBILEK, A.S. and KANSU, I.A., 1996. The influence of rearing medium on the irradiation sensitivity of eggs and larvae of flour beetle, Tribolium confusum. Journal of Stored Products Research, vol. 32, no. 1, pp. 1-6. http://dx.doi.org/10.1016/0022474X(95)00039-A. 